\title{
Enhancement of Photo-bromination of Phenol by Anthraquinone-2-sulphonate and Benzophenone: Implication for Photo-production of Organic Brominated Compounds by Dissolved Organic Matter in Marine Environment
}

Hui Liu ( $\sim$ liuhui@dlmu.edu.cn )

Dalian Maritime University https://orcid.org/0000-0001-8991-9192

Xiaojun Qiu

Dalian Maritime University

Xiaomei Zhu

Dalian Maritime University

\section{Bing Sun}

Dalian Maritime University

Xiaoxing Zhang

Dalian Maritime University

\section{Research Article}

Keywords: anthraquinone-2-sulphonate, benzophenone, photobromination, 3DOM*

Posted Date: March 30th, 2021

DOl: https://doi.org/10.21203/rs.3.rs-315863/v1

License: (c) (i) This work is licensed under a Creative Commons Attribution 4.0 International License. Read Full License 


\section{Abstract}

Organobromine compounds are of great ecological risks due to their high toxicity on organisms. Photochemical halogenation reaction may represent an important natural formation process of natural organobromine compounds in marine environment. Here we reported the enhanced formation of bromophenols from phenol by sunlit anthraquinone-2-sulphonate (AQ2S) and benzophenone (BP) in aqueous bromide solutions. Quinones and aromatic ketones are ubiquitous components of dissolved organic matter (DOM) in surface waters, and AQ2S and BP were adopted here as proxies of DOM. Bromophenols' formation increased with the increasing of the concentrations of $A Q 2 S$ and $B P$, and the promotion effect was in the order AQ2S > BP, indicating that sunlit DOM plays an important role for the formation of reactive bromine species. Chloride was found to promote the formation of bromophenols obviously, suggesting a possible role of the mixed reactive halogen species. Finally, the natural DOM from Suwannee River was found to enhance photobromoination at a low concentration ( $\left.1 \mathrm{mg} \mathrm{L}^{-1}\right)$ in aqueous bromide solution. Our results demonstrated the importance of reactive halogen species generation from sunlit DOM, which possibly contributes to the abiotic source of organohalogen compounds in marine environment.

\section{Introduction}

Halogenated compounds, such as halophenols, are usually environmentally harmful, with a potential to act as or transfer to persistent organic pollutants. In recent years, more and more attention has been paid to the natural formation of halogenated organic compounds in marine environment, especially the photochemical synthesis of organobromine compounds, such as polybrominated diphenyl ether, bromophenols and brominated alkanes (Tamtam and Chiron 2012; Hao et al. 2017; Liu et al. 2020). One reason is that organobromine compounds can be produced through both natural biotic and abiotic processes in marine environment, which plays an important role in the biogeochemical cycling of bromine (Gribble 2003; Méndez-Díaz et al. 2014). More importantly, organobromine compounds can potentially cause more serious adverse health effects, due to their higher cytotoxicity and genotoxicity as compared to their chlorinated analogues (Komaki et al. 2009).

The photochemical formation of organobromine compounds is started by the production of brominated agents, involving radical and non-radical reactive bromine species (RBS), upon photolysis of bromide in the presence of some oxidants or photocatalysts (Calza et al. 2008; Tamtam and Chiron 2012; Hao et al. 2018). A potentially important source of RBS in aqueous solutions is dissolved organic matter (DOM). Absorption of sunlight by DOM leads to the generation of excited triplet states of dissolved organic matter ( ${ }^{3} \mathrm{DOM}^{*}$ ) and reactive oxygen species (ROS) including ${ }^{\circ} \mathrm{OH}$ (Dong and Rosario-Ortiz 2012). Bromide ions are the predominant sink of ${ }^{\circ} \mathrm{OH}$ in seawater, with scavenging rate $~ 93 \%$, resulting in the corresponding reactive halogen species (RHS) (Mopper and Zhou 1990, Parker and Mitch 2016). In addition, direct halide oxidation by ${ }^{3} \mathrm{DOM}^{*}$, previously demonstrated using model triplet sensitizers, provides a seawater-specific, ${ }^{\circ} \mathrm{OH}$-independent RHS production pathway (Canonica et al. 2000; Brigante et 
al. 2014), which could increase overall RHS generation rates. The steady-state concentration of RHS ([RHS $]_{S S}$ ) was estimated to be $2 \times 10^{-14} \mathrm{M}$ (Parker and Mitch, 2016), which was about $10^{3}$ times higher than ['OH] $]_{S S}$. Furthermore, RHS was found to react rapidly with olefinic, aromatic and organosulfur compounds (Zhang and Parker, 2018). However, the role of the resultant RHS in marine environment has not received much attention yet.

As we know, properties of ${ }^{3} \mathrm{DOM}^{*}$ are clearly different for various structures and sources of DOM (Kristopher and Silvio 2016). The question whether ${ }^{3} \mathrm{DOM}^{*}$ can oxidize halide ions depends on its standard reduction potential. The averaged reduction potential obtained in different studies of terrestrial and freshwater DOM reference standards is estimated to be centered near 1.64 $\mathrm{V}_{\mathrm{NHE}}$ (McNeill and Canonica 2016) and about 1.6 1.8 $\mathrm{V}_{\mathrm{NHE}}$ (Parker and Mitch 2016). The estimated one-electron reduction

potentials of the halogens $\mathrm{E}_{\mathrm{X} \cdot \mathrm{X} \text { - }}$ are 1.37 2.59 $\mathrm{V}_{\mathrm{NHE}}$ in water, where $\mathrm{X}=\mathrm{Cl}$, $\mathrm{Br}$ or I (Isse et al. 2011). These values are about 0.4-0.5 $\mathrm{V}_{\mathrm{NHE}}$ lower in polar organic solvents, which is an important consideration because DOM exists as supermolecular aggregates and colloids where the electric field in the vicinity of the chromophoric site may be somewhere in between water and polar organic solvents (Yang and Pignatello 2017). Therefore, bromide and iodide and possibly chloride, are potentially susceptible to oneelectron oxidation by ${ }^{3} \mathrm{DOM}^{*}$. Studies have demonstrated that photochemical transformation of pollutants with DOM in seawater resulted halogenated derives. Tamtam and Chiron (2012) showed that salicylic acid can undergo bromination reaction in sunlit seawater. Hao et al. (2017) found that bromide is oxidized/reduced by the DOM to form RHS, which then reacts with DOM to form brominated and iondated DOM. However, due to the complexity of DOM, it is still unclear that what kind structure of DOM can efficiently lead to RHS formation.

In this study, anthraquinone-2-sulphonate (AQ2S) and benzophenone (BP) were selected as two DOM sample models to illustrate the ability of quinones- and aromatic ketones-like components to generate RHS. It is highly possible that quinone and aromatic ketone structures exist in natural water, since they could be formed through the partial oxidation of lignin precursors (Sharpless and Blough, 2014). Moreover, quinones and aromatic ketones are often representative of the coloured moieties of natural DOM (Cory and McKnight 2005; Maddigapu et al. 2010). The formation of bromophenols from phenol in the presence of $\mathrm{AQ} 2 \mathrm{~S}$ or BP was studied in bromide solutions under the irradiation of the simulated sunlight, and the influence of natural organic matter from Suwannee River (SRNOM) on bromophenols' formation was also assessed in this work.

\section{Materials And Methods}

\subsection{Standards and reagents}

Phenol, 2-bromophenol, 4-bromophenol, AQ2S and BP were purchased from Sigma-Aldrich, and 2hydroxy-5-chlorobiphenyl was purchased from AccuStandard. SRNOM was obtained from International Humic Substances Society (IHSS, Darmstadt, Germany). The UV-vis spectra of AQ2S, BP and SRNOM 
were in Fig. S1. All other chemicals were reagent grade and used as received. Ultrapure water was obtained with a Millipore water purification water unit for preparing all aqueous solutions.

\subsection{Photochemical experiments}

The photochemical experiments were conducted in the simulated sunlight source (Phchem III, Beijing Newbit Technology Co., Ltd) which contains a $500 \mathrm{~W}$ xenon arc lamp and filters to cut off the light with wavelengths below $290 \mathrm{~nm}$, and the light intensity of the solar simulator was $15 \mathrm{~mW} \mathrm{~cm}^{-2}$. Aqueous samples $(100 \mathrm{~mL})$ were held in quartz tubes and cooled by a fan during irradiation; the dark control tubes wrapped in Al foil were also placed in the solar simulator. Two parallel samples were set up in experiments.

\subsection{Chemical analysis}

The amounts of bromophenols were extracted by dichloromethane and then analyzed by gas chromatography mass spectrometry (Agilent 7890 GC and 5975C MSD) using 2-hydroxy-5-chlorobiphenyl as the internal standard. The details are in Text $\mathrm{S} 1$ of the supporting information.

\section{Results And Discussion}

\subsection{Photobromination of phenol in bromide solutions}

Phenol's bromination was first studied in aqueous bromide solutions. The concentration of bromide, $\left[\mathrm{Br}^{-}\right]$, in seawater is at an average concentration of $0.8 \mathrm{mmol} \mathrm{L}^{-1}$, while it can be enriched in the sea-spray aerosols due to the evaporation of water and can reach dozens of $\mathrm{mmol} \mathrm{L}^{-1}$ (Edebeli et al. 2019). Considering the wide $\left[\mathrm{Br}^{-}\right]$range in marine environment and the analytical convenience, $\left[\mathrm{Br}^{-}\right]$adopted in this work was ranged from 0.8 to $80 \mathrm{mmol} \mathrm{L}^{-1}$. Fig. 1 shows that $\sim 10 \mathrm{ng} \mathrm{L}^{-1}$ bromophenols was generated with $8 \mathrm{mmol} \mathrm{L}^{-1} \mathrm{Br}^{-}$, whereas no detectable bromophenols was formed in dark within $8 \mathrm{~h}$. The formation of bromophenols was obviously enhanced with the increasing of [ $\left.\mathrm{Br}^{-}\right]$, with bromophenols concentration reaching $\sim 21 \mathrm{ngL}^{-1}$ in the presence of $80 \mathrm{mmol} \mathrm{L}^{-1} \mathrm{Br}^{-}$.

The production of bromophenols in aqueous systems has be supposed to occur mainly via bromine radicals $\left(\mathrm{Br}_{2}{ }^{-{ }^{-}} / \mathrm{Br}^{*}\right)$ (De Laurentiis et al. 2012; Liu et al. 2018). One formation path of bromine radicals is by oxidation of $\mathrm{OH}$ (eqs. 1-3, $k_{+}$and $k_{-}$represent the forward and backward rate constant, respectively, and the unit of $k$ is $\mathrm{M}^{-1} \mathrm{~s}^{-1}$ ) (Zhang and Parker 2018).

$\cdot \mathrm{OH}+\mathrm{Br}^{-} \rightarrow \mathrm{HBrO}^{\cdot-} k_{+}=1.1 \times 10^{10} \mathrm{M}^{-1} \mathrm{~s}^{-1}, k_{-}=3.3 \times 10^{7} \mathrm{M}^{-1} \mathrm{~s}^{-1}$

$\mathrm{HBrO}^{\circ-}+\mathrm{H}^{+} \rightarrow \mathrm{Br}^{\bullet}+\mathrm{H}_{2} \mathrm{O} \quad k_{+}=4.4 \times 10^{10} \mathrm{M}^{-1} \mathrm{~s}^{-1}, k_{-}=1.36 \mathrm{M}^{-1} \mathrm{~s}^{-1}$

$\mathrm{Br}^{\bullet}+\mathrm{Br}^{-} \rightarrow \mathrm{Br}_{2}^{\cdot-} \quad k_{+}=1.2 \times 10^{10} \mathrm{M}^{-1} \mathrm{~s}^{-1}, k_{-}=6.6 \times 10^{3} \mathrm{M}^{-1} \mathrm{~s}^{-1}$ 
Phenol bromination takes place in two steps, involving a phenoxyl radical formation and bromine radical substitution reaction (eqs. 4 and 5) (Vione et al. 2008). High concentration of bromide helped for $\mathrm{Br}_{2}{ }^{\cdot-}$ formation, consequently led to more generation of bromophenols.

$\mathrm{ArOH}+\mathrm{Br}_{2}^{\cdot-} \rightarrow \mathrm{ArO}^{\cdot}+2 \mathrm{Br}^{-}$

$\mathrm{ArO}^{\circ}+\mathrm{Br}_{2}{ }^{\cdot-} \rightarrow \mathrm{BrArOH}+2 \mathrm{Br}^{-}$

In the reaction system of this work, ${ }^{\circ} \mathrm{OH}$ could be originated from the photolysis of phenol. Jiang et al. (2020) have demonstrated that photolysis of phenolic compounds resulted free radicals including ${ }^{\circ} \mathrm{OH}$ based on the electron paramagnetic resonance investigation. The formation path of ${ }^{\circ} \mathrm{OH}$ from phenol was shown in Fig. S2.

\subsection{Effect of AQ2S and BP on the photobromination of phenol}

Fig. 2 reports the time evolutions of 2-bromophenol (A) and 4-bromophenol (B) upon irradiation of $2 \mathrm{mg}$ $\mathrm{L}^{-1}$ phenol in the presence of 1 and $10 \mu \mathrm{mol} \mathrm{L}^{-1} \mathrm{AQ} 2 \mathrm{~S}$ or BP. AQ2S and BP considerably enhanced the photobromination of phenol, and the concentrations of bromophenols increased with increasing of [AQ2S] and [BP] obviously. The promotion effect of AQ2S was more significant that $B P$, bromophenols reached 110 150 $\mathrm{ng} \mathrm{L}^{-1}$ in the presence of $10 \mu \mathrm{mol} \mathrm{L}^{-1}$ AQ2S, which was about twice of that in the presence of $10 \mu \mathrm{mol} \mathrm{L}^{-1} \mathrm{BP}$. Phenol removal was $\sim 5 \%$ within $8 \mathrm{~h}$ irradiation (Fig. S3), and the convert rate of phenol to bromophenols with $\mathrm{BP}$ or $\mathrm{AQ} 2 \mathrm{~S}$ was $\sim 10^{-3}$. It is not high but may be of significance, for the universal coexistence of DOM and bromides in marine environment.

Apart from oxidation by ${ }^{\circ} \mathrm{OH}$, triplet state of aromatic ketones and quinones can oxidize bromide to $\mathrm{Br}_{2}{ }^{-{ }^{-}}$ as well (Yang and Pignatello 2017). Brigante et al. (2014) and De Laurentiis et al. (2012) previously showed the possibility of sensitized photochemical production of dihalogen radical anions $\mathrm{Cl}_{2}{ }^{\cdot-}$ and $\mathrm{Br}_{2}{ }^{\cdot-}$ from $\mathrm{Cl}^{-}$and $\mathrm{Br}^{-}$, using AQ2S as a sensitizer. Jammoul et al. (2009) found that the triplet excited state of benzophenone can oxidize bromide ions to $\mathrm{Br}_{2}{ }^{\cdot-}$. The oxidation of bromide by excited triplet state $\left({ }^{3} \mathrm{~S}\right)$ of aromatic ketones and quinones is considered to via charge-transfer interactions, and can be confined to the reduction potential of ${ }^{3} \mathrm{~S}$. Excited triplet state of $A Q 2 S\left({ }^{3} \mathrm{AQ} 2 \mathrm{~S}^{*}\right)$ is a powerful oxidant $\left(\mathrm{E}_{3 \mathrm{~S} / \mathrm{S}-}=2.28\right.$ $\mathrm{V}_{\mathrm{NHE}}$ ), and aromatic ketones possess triplet state reduction potentials of 1.10 1.69 $\mathrm{V}_{\mathrm{NHE}}$ (McNeill and Canonica 2016). Therefore, it is reasonable to propose that ${ }^{3} \mathrm{AQ} 2 \mathrm{~S}^{*}$ and ${ }^{3} \mathrm{BP}^{*}$ could oxidize $\mathrm{Br}^{-}$to $\mathrm{Br}_{2}{ }^{\cdot-}$ (eq. 6).

${ }^{3} \mathrm{AQ} 2 \mathrm{~S}^{*}$ or ${ }^{3} \mathrm{BP}^{*}+2 \mathrm{Br}^{-} \rightarrow \mathrm{AQ} 2 \mathrm{~S}^{\cdot-}$ or $\mathrm{BP}^{\cdot-}+\mathrm{Br}_{2}{ }^{\cdot-}$

In addition, ${ }^{3} \mathrm{AQ} 2 \mathrm{~S}^{*}$ and ${ }^{3} \mathrm{BP}^{\star}$ can oxidize phenol via an electron transfer reaction, forming phenoxyl radical, which is also an important process for bromophenol generation. Jammoul et al. (2009) have demonstrated that the quenching of triplet state of benzophenone, ${ }^{3}\left(\operatorname{Ar}_{1} \mathrm{Ar}_{2}-\mathrm{C}=0\right)^{*}$, with phenol occurred 
by electron transfer. The electron transfer reaction is usually described by a mechanism involving (i) formation of a precursor complex, $\left.\left[\mathrm{PhOH}_{. .}{ }^{3}\left(\mathrm{Ar}_{1} \mathrm{Ar}_{2}-\mathrm{C}=\mathrm{O}\right)\right)^{*}\right]$, (ii) electron transfer to form a charge transfer (CT) complex, $\left[\mathrm{PhOH}^{\cdot+} . . . \mathrm{Ar}_{1} \mathrm{Ar}_{2}-\mathrm{C}^{\circ}-\mathrm{O}^{-}\right]$, and (iii) separation of the oxidized donor and reduced acceptor, yielding a protonated phenoxyl radical $\left(\mathrm{PhOH}^{\cdot+}\right)$ and a deprotonated ketyl radical $\left(\mathrm{Ar}_{1} \mathrm{Ar}_{2}-\mathrm{C}^{\circ}-\mathrm{O}^{-}\right)$, eq 7 . $\mathrm{PhOH}^{++}$is a strong acid with $p K_{a}$ of -2.0 (Canonica et al. 2000), and is liable to give out one proton forming phenoxy radical (eq. 8).

$\mathrm{PhOH}+{ }^{3}\left(\mathrm{Ar}_{1} \mathrm{Ar}_{2}-\mathrm{C}=0\right)^{*} \rightleftarrows\left[\mathrm{PhOH}_{. .}{ }^{3}\left(\mathrm{Ar}_{1} \mathrm{Ar}_{2}-\mathrm{C}=0\right)^{*}\right] \rightleftarrows\left[\mathrm{PhOH}^{\cdot+} \ldots \mathrm{Ar}_{1} \mathrm{Ar}_{2}-\mathrm{C}^{*}-\mathrm{O}^{-}\right] \rightarrow \mathrm{PhOH}^{++}+\mathrm{Ar}_{1} \mathrm{Ar}_{2}-\mathrm{C}^{*}-\mathrm{O}^{-}$

$\mathrm{PhOH}^{+} \rightarrow \mathrm{PhOH}^{*}+\mathrm{H}^{+}$

The rate constants for eq. 6 and eq.7 follows the order AQ2S > BP, which is consistent with the order of their reduction potential. The reduction potentials, $\mathrm{E}_{3 \mathrm{~S} / \mathrm{S}-\text {, }}$ for $\mathrm{BP}$ and $\mathrm{AQ} 2 \mathrm{~S}$ are $1.67 \mathrm{~V}_{\mathrm{NHE}}$ and $2.28 \mathrm{~V}_{\mathrm{NHE}}$ respectively. Therefore, the promotion effect of $A Q 2 S$ on phenol bromination was more obvious than that of BP.

In addition, although there ensued a long-lasting controversy about the possibility for excited AQ2S to generate ${ }^{\circ} \mathrm{OH}$ upon oxidation of water, some studies have indicated the possibility that free ${ }^{\circ} \mathrm{OH}$ was being formed with significant amounts (Alegía et al. 1999; Maurino et al. 2008). Therefore, AQ2S promoted phenol bromination via generating ${ }^{\circ} \mathrm{OH}$ as well as ${ }^{3} \mathrm{AQ} 2 \mathrm{~S}^{*}$, which are helpful for bromine radicals and phenoxyl radical production.

\subsection{Effect of bromide and chloride concentrations}

Formation of bromophenols in the presence of $10 \mu \mathrm{mol} \mathrm{L}^{-1} \mathrm{BP}$ or AQ2S with different concentration of bromide is shown in Fig. 3 . It is clear that bromophenols increased obviously with $\left[\mathrm{Br}^{-}\right]$ranging from 0.8 to $80 \mathrm{mmol} \mathrm{L}^{-1}$. Take 2-bromophenols for example, [2-bromophenol] was around 10, 35 and $65 \mathrm{ng} \mathrm{L}^{-1}$ in the presence of $\mathrm{BP}$, while it was about 13,85 and $110 \mathrm{ng} \mathrm{L}^{-1}$ in the presence of $A Q 2 \mathrm{~S}$, with $\left[\mathrm{Br}^{-}\right]$ranging from 0.8 to $80 \mathrm{mmol} \mathrm{L}^{-1}$.

Bromine radical was the dominant precursor for the formation of bromophenols. According to the model proposed by Loeff et al. (1993), halide reacts with the triplet excited state $\left({ }^{3} S\right)$ to form a charge-transfer binary exciplex, ${ }^{3}\left(\mathrm{~S}^{{ }^{--}-\mathrm{X}}\right)$, and ternary exciplex, ${ }^{3}\left(\mathrm{~S}^{\cdot-}-\mathrm{Br}^{\circ}-\mathrm{Br}^{-}\right)$, both of which can decay to the ground state or dissociate to the radical pairs, as shown in Fig. S4. The ternary exciplex has a lower tendency than the binary exciplex to decay to the ground state since it has weaker spin-orbit coupling of the incipient radical. Consequently, ternary exciplex dissociates to the radical products, $\mathrm{Br}_{2}{ }^{\circ-}$, more favorably than the binary exciplex. High concentrations of halide could favor ternary exciplex formation, thus increase the generation of bromophenols.

Considering chloride is the main anion in seawater, the effect of chloride on phenol bromination was studied next. Fig. 4 shows addition of $0.5 \mathrm{~mol} \mathrm{~L}^{-1}$ chloride enhanced the formation of bromophenols 
obviously, especially in the presence of AQ2S (Fig. 4C and D). As mentioned above, high concentration of chloride helped to generate ternary exciplex, ${ }^{3}\left(\mathrm{~S}^{--}-\mathrm{Br}^{\circ}-\mathrm{Cl}^{-}\right)$, which then formed the mixed dihalogen radical anion, $\mathrm{BrCl}^{-}$. Subsequently, $\mathrm{BrCl}^{--}$reacted with $\mathrm{Br}^{-}$to produce $\mathrm{Br}_{2}{ }^{\circ-}$ (eq. 9). On the other hand, ${ }^{\circ} \mathrm{OH}$ can oxidize $\mathrm{X}^{-}$to produce reactive radical species, $\mathrm{X}^{*} / \mathrm{X}_{2}{ }^{--}$, through $\mathrm{HXO}{ }^{\circ-}$, where $\mathrm{X}=\mathrm{Br}, \mathrm{Cl}$ (Zhang and Parker 2018; Dong et al. 2020). Although $\mathrm{Cl}^{-}$is an ineffective ${ }^{\circ} \mathrm{OH}$ scavenger since the intermediate $\mathrm{HClO}^{--}$primarily reverts to ${ }^{\circ} \mathrm{OH}$ and $\mathrm{Cl}^{-}$not to $\mathrm{Cl}^{\circ}$ (eq. 10 ), $\mathrm{HClO}^{--}$is liable to react with $\mathrm{Br}^{-}$to form $\mathrm{BrCl}^{\circ-}$ (eq. 11). Reactions related to $\mathrm{BrCl}^{--}$are expected to be predominant in marine environment, since bromide is susceptibly oxidized while chloride is abundant. Consequently, chloride enhanced bromophenols production due to the generation of $\mathrm{BrCl}^{\cdot-}$ and the subsequent formation of $\mathrm{Br}_{2}{ }^{\cdot-}$.

$\mathrm{BrCl}^{--}+\mathrm{Br}^{-} \rightarrow \mathrm{Br}_{2}^{\cdot-}+\mathrm{Cl}^{-} \quad k_{+}=8.0 \times 10^{9} \mathrm{M}^{-1} \mathrm{~s}^{-1}, k_{-}=4.3 \times 10^{6} \mathrm{M}^{-1} \mathrm{~s}^{-1}$

$\cdot \mathrm{OH}+\mathrm{Cl}^{-} \rightleftarrows \mathrm{HClO}^{--} \quad k_{+}=4.0 \times 10^{9} \mathrm{M}^{-1} \mathrm{~s}^{-1}, k_{-}=6.0 \times 10^{9} \mathrm{M}^{-1} \mathrm{~s}^{-1}$

$\mathrm{HClO}^{--}+\mathrm{Br}^{-} \rightarrow \mathrm{BrCl}^{--}+\mathrm{OH}^{-} \quad k_{+}=1.0 \times 10^{9} \mathrm{M}^{-1} \mathrm{~s}^{-1}, k_{-}=3.0 \times 10^{6} \mathrm{M}^{-1} \mathrm{~s}^{-1}$

Fig. $4 \mathrm{C}$ and $\mathrm{D}$ shows that bromophenols' concentration in the presence of $\mathrm{AQ} 2 \mathrm{~S}$ reached approximate 5000 10000 $\mathrm{ng} \mathrm{L}^{-1}$ after adding chloride, which was almost 100 times higher than that without chloride. Brigante et al. (2014) have demonstrated that ${ }^{3} A Q 2 S^{*}$ could oxidize chloride to generate chlorine radical. $E_{3 S / S-}$ of $A Q 2 S$ is $2.28 V_{N H E}$, thus it can oxidize $\mathrm{Cl}^{-}$and $\mathrm{Br}^{-}$to generate mixed-halogen radical, $\mathrm{BrCl}^{{ }^{--}}$(eq. 12) and subsequently generate $\mathrm{Br}_{2}{ }^{-{ }^{-}}$(eq. 9) (Zhang and Parker 2018). Therefore, the promotion effect of chloride on the bromophenols' formation was really significant with AQ2S. In contrast, the promotion effect of chloride in the presence of BP was not so obvious (Fig. 4 A and B), which should be attributed to the lower oxidizing ability of ${ }^{3} \mathrm{BP}^{*}$. Although no data are available for the reduction potential of $\mathrm{BrCl}^{\circ}$, it is typically assumed to present reduction potential between or similar to $\mathrm{Br}_{2}{ }^{\cdot-}\left(\mathrm{E}_{\mathrm{Br} 2 \cdot-/ \mathrm{Br}-}=1.63 \mathrm{~V}_{\mathrm{NHE}}\right)$ and $\mathrm{Cl}_{2}{ }^{\cdot-}\left(\mathrm{E}_{\mathrm{Cl} 2 \cdot-/ \mathrm{Cl}-}=2.20 \mathrm{~V}_{\mathrm{NHE}}\right)$. $\mathrm{E}_{3 \mathrm{~S} / \mathrm{S}-}$ for $\mathrm{BP}$ is $1.67 \mathrm{~V}_{\mathrm{NHE}}$, so ${ }^{3} \mathrm{BP}^{\star}$ did not efficiently produce $\mathrm{BrCl}^{--}$, consequently the promotion effect of chloride in the presence of BP was much lower than that of AQ2S.

${ }^{3} \mathrm{AQ} 2 \mathrm{~S}^{*}+\mathrm{Br}^{-}+\mathrm{Cl}^{-} \rightarrow{ }^{3}\left[\mathrm{AQ} 2 \mathrm{~S}^{-}-\mathrm{Br}^{-}-\mathrm{Cl}^{-}\right] \rightarrow{ }^{3} \mathrm{AQ} 2 \mathrm{~S}^{--}+\mathrm{BrCl}^{--}$

It is noticeable that the concentrations of 4-bromophenol were higher that 2-bromophenol in almost all cases, especially in Fig. 4C and D. The similar result has been observed by Vione et al (2008), which was attributed to the higher formation rate of 4-bromophenol compared to 2-bromophenol. The higher formation rate of the para isomer as compared to the ortho isomer might be explained by a lower steric hindrance at the para position, which is more distant from the oxygen atom, that could allow easier addition of the bulky $\mathrm{Br}$ atom to the aromatic ring (Vione et al. 2008). In addition, Zakon et al. (2013) found that 4-bromophenol degraded much slower than 2-bromophenol during photolysis. Consequently, 4-bromophenol was easier to be accumulated in the solutions.

3.4 Formation of bromophenols in the presence of SRNOM 
The effects of SRNOM on phenol bromination were shown in Fig. 5. Bromophenols reached more than 30 $\mathrm{ng} \mathrm{L}{ }^{-1}$ with $1 \mathrm{mg} \mathrm{L}^{-1}$ SRNOM, which was about three times of that without DOM, indicating that SRNOM enhanced bromophenols formation. However, when SRNOM increased to $5 \mathrm{mg} \mathrm{L}^{-1}$, bromophenols decreased, which could be attributed to the competitive consumption of RBS by DOM forming halogenated DOM or light shielding effect (Hao et al. 2017; Dong et al. 2020).

Irradiation of DOM with solar light generates ${ }^{3} \mathrm{DOM}^{*}$ and ${ }^{\circ} \mathrm{OH}$, which both act as oxidants to oxidize halide ions. The photogeneration of bromine radicals in marine environment can take place upon bromide photooxidation of ${ }^{\circ} \mathrm{OH}$ (reaction 1 3) and ${ }^{3} \mathrm{DOM}^{*}$ (eq. 13 and 14). Although $\mathrm{ClBr}^{*-}$ is predicted to be the dominant RHS formed initially via halide oxidation by ${ }^{3} \mathrm{DOM}^{*}$ in seawater, Parker and Mitch et al. (2016) found that $\mathrm{Br}_{2}{ }^{\cdot-}$ concentrations may exceed those of $\mathrm{ClBr}^{\cdot-}$ by $\sim 2.5$-fold, because the dominance of $\mathrm{Br}_{2}{ }^{\cdot-}$ arises from further reactions of $\mathrm{ClBr}^{\circ-}$ (e.g., with $\mathrm{Br}^{-}$). Therefore, $\mathrm{ClBr}^{--}$was an important intermediate for bromination reaction.

${ }^{3} \mathrm{DOM}^{*}+2 \mathrm{Br}^{-} \rightarrow \mathrm{DOM}^{\cdot-}+\mathrm{Br}_{2}^{\cdot-}$

${ }^{3} \mathrm{DOM}^{\star}+\mathrm{Br}^{-}+\mathrm{Cl}^{-} \rightarrow{ }^{3} \mathrm{DOM}^{\cdot-}+\mathrm{BrCl}^{\cdot-}$

As far as eq. 13 and 14 are concerned, it is decided that the halogen radicals generation depends on the oxidation capability of ${ }^{3} \mathrm{DOM}^{*}$ which is determined by DOM structure. Although the relationship between the oxidation capability and the structure of DOM needs further investigation, it is undeniable that organic compounds with quinone and aromatic ketone structure can accelerate the bromination reaction. As we know, river DOM mainly contains humic- or fulvic-like components while marine DOM mainly contains protein- or amino acid-like component, whereas river DOM exists in estuarine and coastal aqueous environment due to the mixture of river and sea water. Nevertheless, this result justified the enhancement of DOM for the photochemical bromination reaction in the saline water that is relevant to the marine environment.

Although this research focused on aqueous conditions, RHS formation from direct halide oxidation by ${ }^{3} \mathrm{DOM}^{*}$ likely also applies to marine aerosols, where halide concentrations can exceed those in seawater (Finlayson-Pitts 2003). Since non-radical dihalogen species form as products of radical RHS reactions, e.g., $2 \mathrm{ClBr}^{-} \rightarrow \mathrm{ClBr}+\mathrm{Br}^{-}+\mathrm{Cl}^{-}$, this pathway may contribute to the release of halogens to the atmosphere, with implications for tropospheric ozone degradation.

\section{Conclusion}

Here it was shown that AQ2S and BP enhanced the photochemical bromination of phenol, with the promotion effects of $A Q 2 S>B P$. These results indicated that DOM with quinone and aromatic ketone structures could promote photochemical bromination reaction. Chloride obviously promoted the formation of bromophenols, suggesting an important role of the mixed reactive halogen species. These 
results demonstrated the importance of direct halide oxidation of ${ }^{3} \mathrm{DOM}^{*}$ for RHS generation in marine environment.

\section{Declarations}

\section{Conflicts of interest}

There are no conflicts to declare.

\section{Funding}

This study was supported by the National Natural Science Foundation of China (No. 41576111, 11975063), and Fundamental Research Funds for the Central Universities (No. 3132020144).

\section{References}

1. Alegría AE, Ferrer A, Santiago G et al (1999) Photochemistry of water-soluble quinones. Production of the hydroxyl radical, singlet oxygen and the superoxide ion. J Photochem Photobiol A:Chem 127:5765

2. Brigante $M$, Minella $M$, Mailhot $G$ et al (2014) Formation and reactivity of the dichloride radical $\left(\mathrm{Cl}_{2}{ }^{-}\right)$ in surface waters: a modelling approach. Chemosphere 95:464-469

3. Calza P, Massolino C, Pelizzetti E et al (2008) Solar driven production of toxic halogenated and nitroaromatic compounds in natural seawater. Sci Total Environ 398:196-202

4. Canonica S, Hellrung B, Wirz J (2000) Oxidation of phenols by triplet aromatic ketones in aqueous solution. J Phys Chem A104:1226-1232

5. Cory RM, McKnight DM (2005) Fluorescence spectroscopy reveals ubiquitous presence of oxidized and reduced quinones in dissolved organic matter. Environ Sci Technol 39:8142-8149

6. De Laurentiis E, Minella M, Maurino V et al (2012) Assessing the occurrence of the dibromide radical $\left(\mathrm{Br}_{2}{ }^{-}\right)$in natural waters: Measures of triplet-sensitised formation, reactivity, and modelling. Sci Total Environ 439:299-306

7. Dong MM, Rosario-Ortiz FL (2012) Photochemical formation of hydroxyl radical from effluent organic matter. Environ Sci Technol 46:3788-3794

8. Dong YX, Peng WY, Liu YJ et al (2020) Photochemical origin of reactive radicals and halogenated organic substances in natural waters: A review. J Hazard Mater 401:123884

9. Edebeli J, Ammann M, Bartels-Rausch T (2019) Microphysics of the aqueous bulk counters the water activity driven rate acceleration of bromide oxidation by ozone from 289-245 K. Environ Sci-Proc Impacts 21:63-73

10. Finlayson-Pitts BJ (2003) The tropospheric chemistry of sea salt: A molecular-level view of the chemistry of $\mathrm{NaCl}$ and $\mathrm{NaBr}$. Chem Rev 103:4801-4822 
11. Gribble GW (2003) The diversity of naturally produced organohalogens. Chemosphere 52:289-297

12. Hao ZN, Yin YG, Cao D et al (2017) Probing and comparing the photobromination and photoiodination of dissolved organic matter by using ultra-high-resolution mass spectrometry. Environ Sci Technol 51: 5464-5472

13. Hao ZN, Wang J, Yin YG et al (2018) Abiotic formation of organoiodine compounds by manganese dioxide induced iodination of dissolved organic matter. Environ Pollut 236:672-679

14. Isse AA, Lin CY, Coote ML et al (2011) Estimation of standard reduction potentials of halogen atomsand alkyl halides J Phys Chem B 115:678-684

15. Jammoul A, Dumas S, D'Anna B et al (2009) Photoinduced oxidation of sea salt halides by aromatic ketones: a source of halogenated radicals. Atmos Chem Phys 9:4229-4237

16. Jiang JQ, Zhao HX, Xia DM et al (2020) Formation of free radicals by direct photolysis of halogenated phenols (HPs) and effects of DOM: A case study on monobromophenols. J Hazard Mater 391: 122220

17. Komaki Y, Pals J, Wagner ED et al (2009) Mammalian cell DNA damage and repair kinetics of monohaloacetic acid drinking water disinfection byproducts. Environ Sci Technol 43:8437-8442

18. Kristopher M, Silvio C (2016). Triplet state dissolved organic matter in aquatic photochemistry: reaction mechanisms, substrate scope, and photophysical properties. Environ Sci-Proc Impacts, 18, 1381-1399.

19. Liu H, Tong T, Pu Y et al (2020) Methyl bromide production from dissolved organic matter under simulated sunlight irradiation and the important effect of ferric ions. Environ Sci-Proc Impacts 22:751-758

20. Liu YZ, Yang Y, Pang SY et al (2018) Mechanistic insight into suppression of bromate formation by dissolved organic matters in sulfate radical-based advanced oxidation processes. Chem Eng $\mathrm{J}$ 333:200-205

21. Loeff I, Rabani J, Treinin A et al (1993) Charge transfer and reactivity of $n \pi^{\star}$ and $л \pi^{\star}$ organic triplets, including anthraquinone-sulfonates, in interactions with inorganic anions: A comparative study based on classical Marcus theory. J Am Chem Soc 115:8933-8942

22. Maddigapu PR, Minero C, Maurino V et al (2010) Enhancement by anthraquinone-2-sulphonate of the photonitration of phenol by nitrite: Implication for the photoproduction of nitrogen dioxide by coloured dissolved organic matter in surface waters. Chemosphere 81:1401-1406

23. Maurino V, Borghesi D, Vione D et al ( 2008) Transformation of phenolic compounds upon UVA irradiation of anthraquinone-2-sulfonate. Photoch Photobio Sci 7:321-327

24. Méndez-Día JD, Simabuku KK, Ma J et al (2014) Sunlight-driven photochemical halogenation of dissolved organic matter in seawater: A natural abiotic source of organobromine and organoiodine. Environ Sci Technol 48:7418-7427

25. McNeill K, Canonica S (2016) Triplet state dissolved organic matter in aquatic photochemistry: reaction mechanisms, substrate scope, and photophysical properties. Environmental Science. Proc Imp 18:1381-1399 
26. Mopper K, Zhou X (1990) Hydroxyl radical photoproduction in the sea and its potential impact on marine processes. Science 250:661-664

27. Parker KM, Mitch WA (2016) Halogen radicals contribute to photooxidation in coastal and estuarine waters. P Natl Acad Sci USA 113:5868-5873

28. Sharpless CM, Blough NV (2014) The importance of charge-transfer interactions in determining chromophoric dissolved organic matter (CDOM) optical and photochemical properties. Environ SciProc Imp 16ه654

29. Tamtam F, Chiron S (2012) New insight into photo-bromination processes in saline surface waters: The case of salicylic acid. Sci Total Environ 435-436, 345-350

30. Vione D, Maurino V, Man SC et al (2008) Formation of organobrominated compounds in the presence of bromide under simulated atmospheric aerosol conditions. ChemSusChem 1:197-204

31. Yang Y, Pignatello JJ (2017) Participation of the halogens in photochemical reactions in natural and treated Waters. Molecules 22:1684

32. Zakon Y, Halicz L, Gelman F (2013) Bromine and carbon isotope effects during photolysis of brominated phenols. Environ Sci Technol 47:4147-14153

33. Zhang K, Parker KM (2018) Halogen radical oxidants in natural and engineered aquatic systems. Environ Sci Technol 52:9579-9594

\section{Figures}
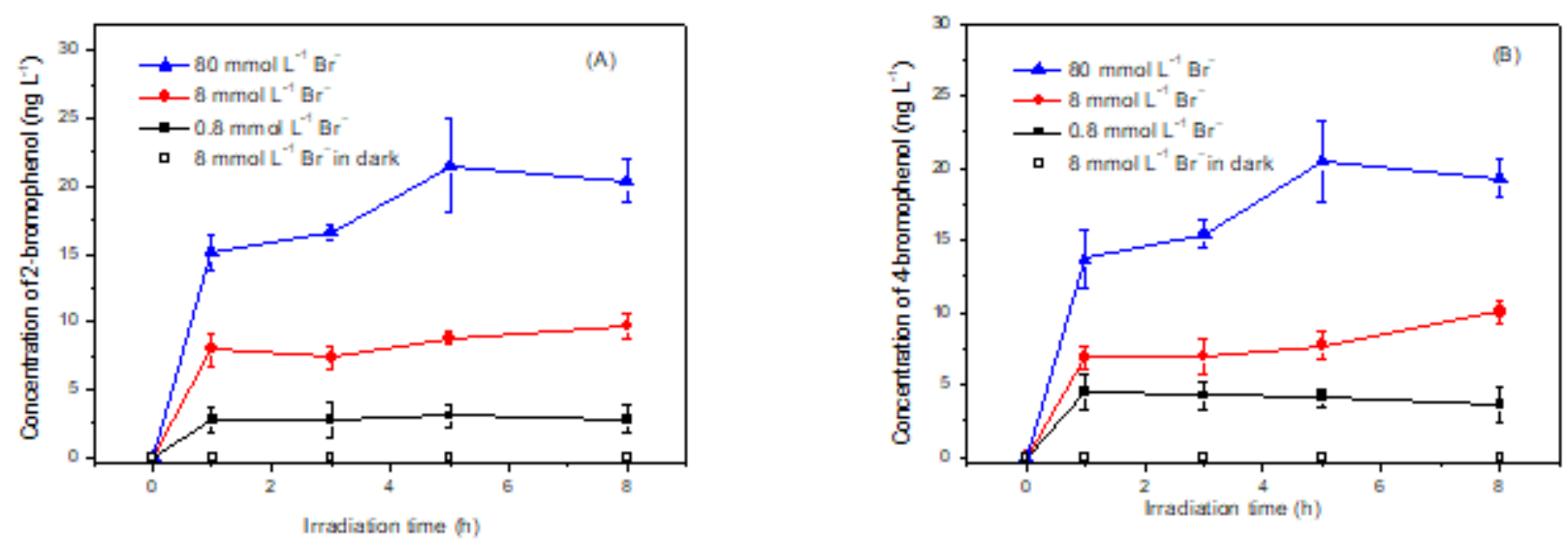

Figure 1

Effect of bromide concentration on the photochemical generation of 2-bromophenol (A) and 4bromophenol (B) with $2 \mathrm{mg} \mathrm{L-1}$ phenol. 

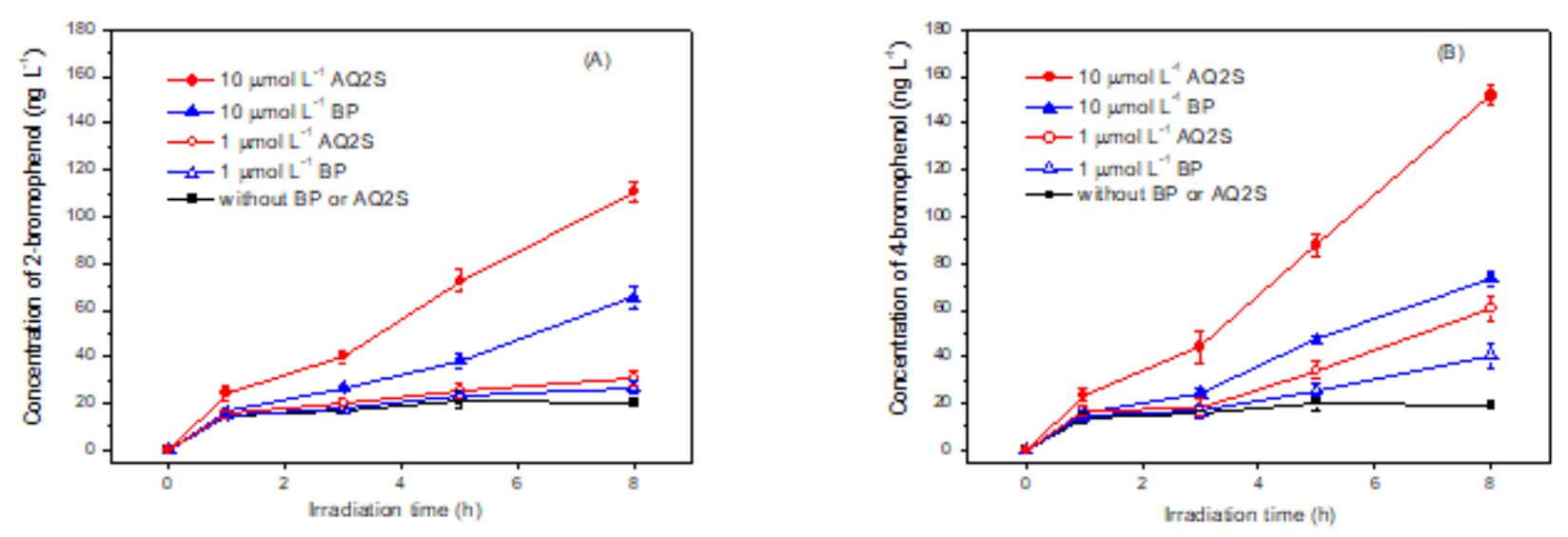

Figure 2

Effect of BP and AQ2S on the photochemical generation of 2-bromophenol (A) and 4-bromophenol (B) in the presence of $80 \mathrm{mmol} \mathrm{L-1} \mathrm{Br}-$ and $2 \mathrm{mg} \mathrm{L}-1$ phenol.
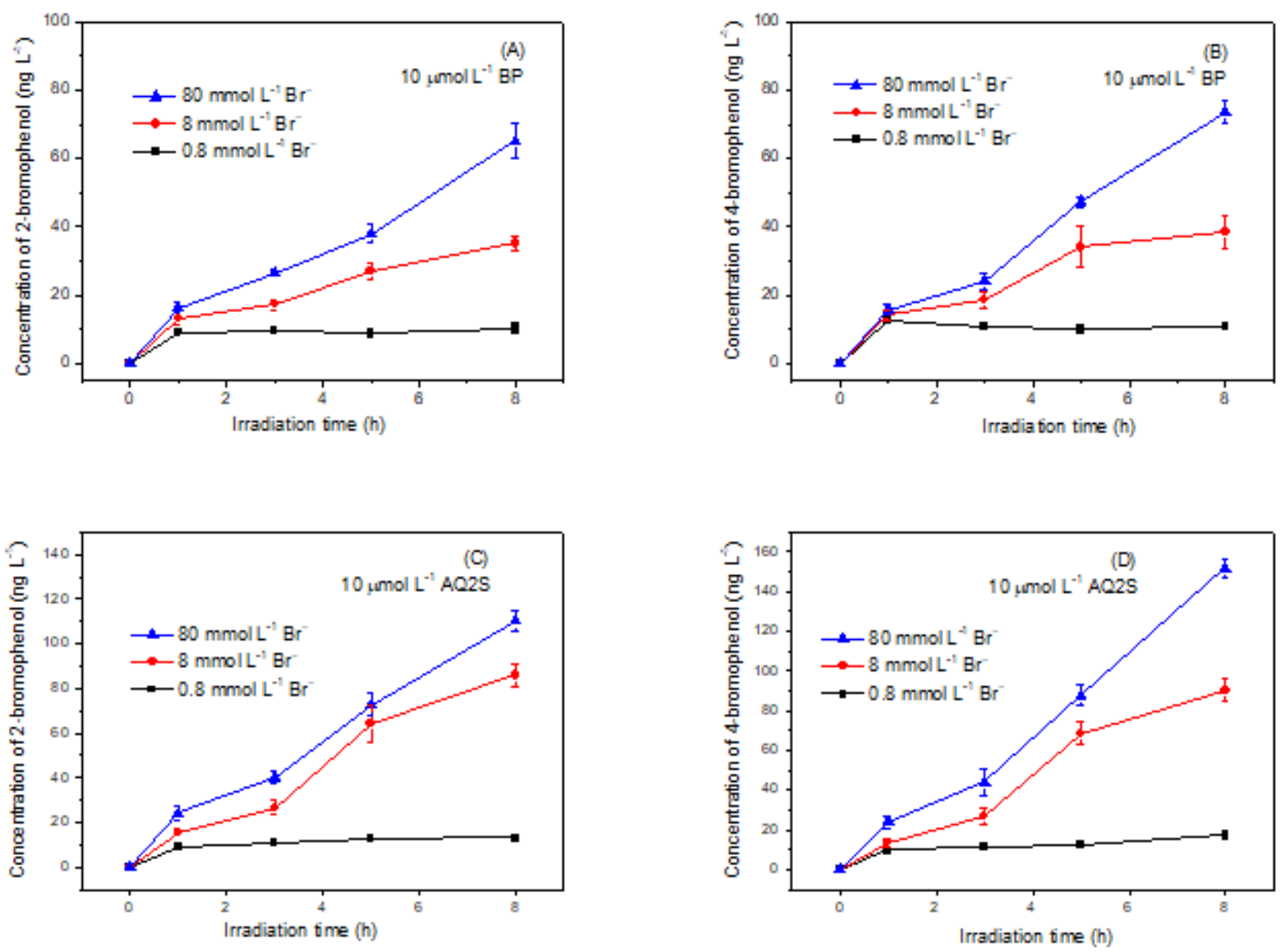

\section{Figure 3}

Effect of bromide concentration on the formation of 2-bromophenol (A, C) and 4-bromophenol (B, D) in the presence of $10 \mu \mathrm{mol} L-1 \mathrm{BP}(\mathrm{A}, \mathrm{B})$ and $10 \mu \mathrm{mol} \mathrm{L}-1 \mathrm{AQ} 2 \mathrm{~S}(\mathrm{C}, \mathrm{D})$ and $2 \mathrm{mg} \mathrm{L}-1$ phenol. 

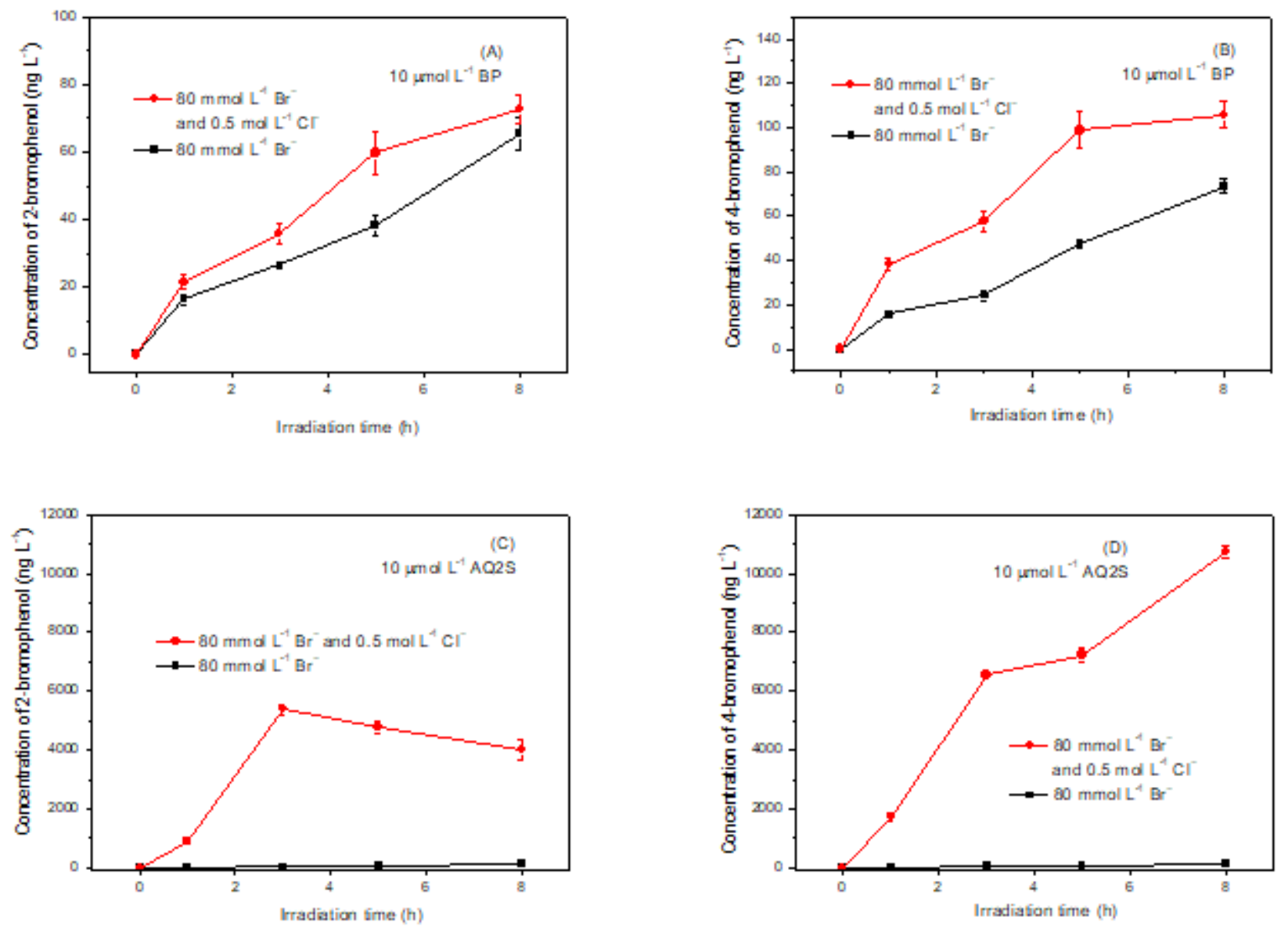

\section{Figure 4}

Effect of chloride ions on the formation of 2-bromophenol (A, C) and 4-bromophenol (B, D) with $10 \mu \mathrm{mol}$ $\mathrm{L}-1 \mathrm{BP}(\mathrm{A}, \mathrm{B})$ or $10 \mu \mathrm{mol} \mathrm{L}-1 \mathrm{AQ} 2 \mathrm{~S}(\mathrm{C}, \mathrm{D})$ in the presence of $2 \mathrm{mg} \mathrm{L}-1$ phenol.
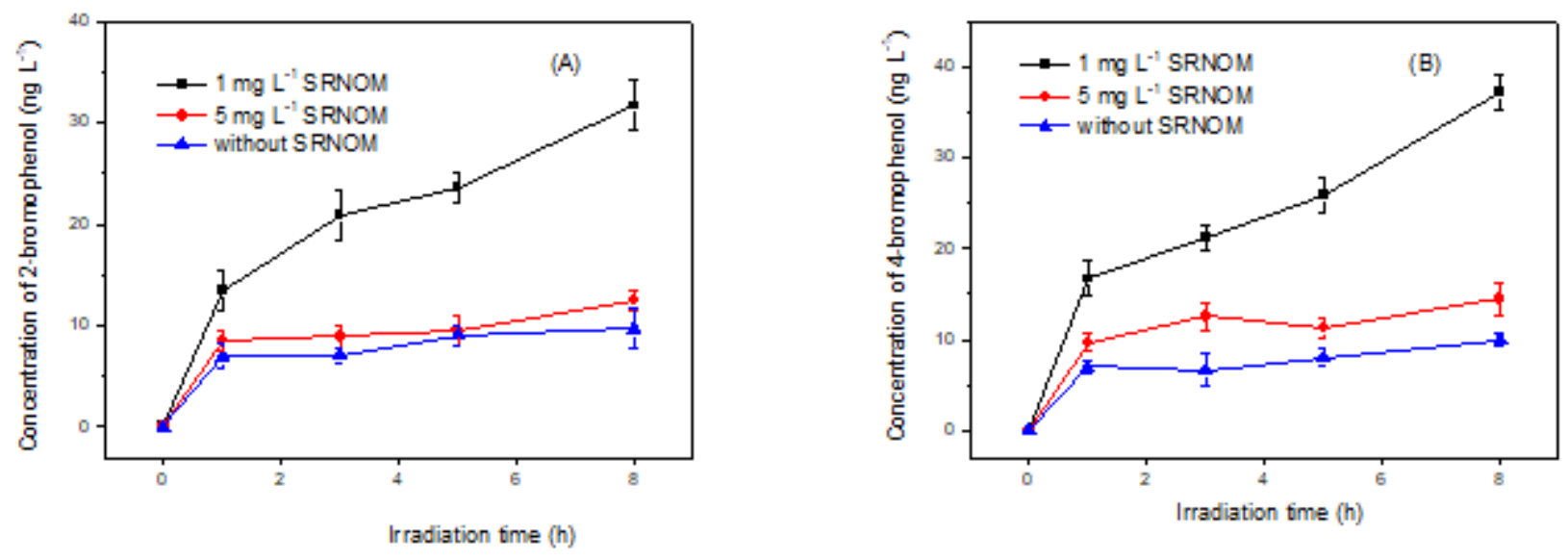

Figure 5 
Photochemical formation of 2-bromophenol (A) and 4-bromophenol (B) in the presence of SRNOM with 2 mg L-1 phenol, 8 mmol L-1 Br- and 0.5 mol L-1 Cl-.

\section{Supplementary Files}

This is a list of supplementary files associated with this preprint. Click to download.

- supportinginformation.docx 